\title{
The maltreatment-violence link: exploring the role of maltreatment experiences and other individual and social risk factors among young people who offend.
}

\begin{abstract}
Objective: This study investigated the extent to which violent offending in a population of young people detained in secure care facilities is related to variations in child maltreatment after controlling for other known individual and social correlates of crime. Method: Official child protection and youth justice records and survey information for 1,819 young people were analyzed. Measures included: maltreatment factors (including type, timing and recurrence); outof-home care placement factors (including type, age at first placement, stability and duration of placements); social factors (including family and peer risk indicators); and individual factors (including factors relating to intelligence and education, substance use, mental health problems, and behavior). Gender and cultural background were also investigated as potential moderating factors. Logistic regression was used to determine the independent effect of maltreatment factors on violent convictions in the presence of other risk factors. Results: Persistent maltreatment was a consistent predictor of violent convictions. Other independent predictors included: aggression, anger, Indigenous status, and male gender, with household conflict also approaching significance. Conclusion: Collaborative and integrated responses from both child protection and juvenile justice may be needed if comprehensive violence prevention strategies are to be developed for young offenders.
\end{abstract}

Keywords: maltreatment; out-of-home care; youth offending; violence; anger; aggression.

\section{Highlights}

- Persistent maltreatment is strongly associated with violent offending.

- Gender and cultural background play a moderating role between maltreatment, placement and violence.

- Anger and aggression play a moderating role in the maltreatment-violence link. 
Violence is a global criminal justice and public health issue which has widespread social and economic consequences requiring policies and interventions that prevent both its onset and development (World Health Organisation, 2002). There is now a robust body of evidence to suggest that the risk for violent offending is greater amongst victims of maltreatment, but it is also recognized that this association is often likely to be moderated or mediated by a range of individual psychological and social factors (for reviews see Malvaso, Delfabbro \& Day, 2016; Wilson et al., 2009). In general, this research shows that only a small proportion of victims of abuse will go on to commit violent offenses and it is likely that not all forms of child and adolescent maltreatment are equally associated with subsequent risk. While these associations are generally well known, relatively little is known about how variations in maltreatment experiences influence the nature and degree of offending. In this study, we attempt to gain insights into which aspects of maltreatment appear to be most strongly associated with violent offending by studying a sample of youth who were placed in secure care under Youth Justice supervision in Australia, but after controlling for other individual and social risk factors. The following review summarizes the conceptual, theoretical and methodological issues taken into account in the analytical design as well as the choice of variables included for investigation.

\section{Maltreatment experiences among young people involved in the criminal justice system}

In general, relatively few detailed studies of maltreated young people have been undertaken using juvenile justice data (Ryan, 2006). Instead, most of these have been limited to descriptive analyses of the prevalence of maltreatment or victimization histories in young offender samples (for a review see Wilson et al., 2009), although some studies have also considered recidivism rates among young offenders who have a history of maltreatment or outof-home care (OHC) placements (Huang, Ryan, Sappleton, \& Chiu, 2015; Ryan, 2006; van der Put $\&$ de Ruiter, 2016). Some of these studies have estimated that up to 89 per cent of detained or incarcerated youth have histories of maltreatment or placement (Halemba \& Lord, 2005; 
Halemba, Siegel, Lord, \& Zawacki, 2004). In Australia, a recent study reported that just over 70 per cent of young people detained in secure care had a child protection history, defined as notifications or substantiations for abuse and/or neglect or a history of placement in OHC (Malvaso, Delfabbro \& Day, 2017a).

An exception to this is the growing body of work on adverse childhood experiences (ACEs) among juvenile offenders (e.g., Baglivio et al., 2016; Baglivio \& Epps, 2016; Wolff \& Baglivio, 2017). ACEs include measures of child abuse and neglect, as well as other traumatic or stressful life events, such as parental separation or divorce, parental incarceration and house mental illness, substance misuse and mental illness. This research suggests that many ACEs are interrelated and exposure differs by gender and cultural background (Baglivio \& Epps, 2015), therefore demonstrating the need to assess and investigate the effects of multiple ACEs among different subgroups of youth offenders.

However, investigations of the maltreatment-offending association among more serious or “deep-end" youth offenders, for example, those detained or placed in juvenile justice facilities are even more limited (Baglivio, Wolff, Piquero, et al., 2016). The Incarcerated Serious and Violent Young Offender study (Yang, McCuish, \& Corrado, 2017), however, indicated that young people with a history of placement in $\mathrm{OHC}$ were more likely to be chronic offenders, with a disproportionate number continuing their offending into early adulthood. Other research has also shown that young people with $\mathrm{OHC}$ experiences start committing crimes earlier, are involved in a greater number of offenses and are incarcerated for longer periods of time (Malvaso \& Delfabbro, 2015; McFarlane, 2015; Ryan, Herz, Hernandez, \& Marshall, 2007). There have also been a number of longitudinal studies which have examined possible pathways from maltreatment to youth offending (see Malvaso et al. 2016 for a review). Although these studies tend to use community or child protection samples and focus only on the initiation of offending or first contact with the police or justice system, the findings from this body of 
research can be used to inform studies on serious and violent offenders because they identify potentially important risk factors for offending.

\section{Child maltreatment factors associated with subsequent youth offending}

Evidence suggests that it is important to avoid treating child maltreatment as a dichotomous variable. Such an approach fails to consider the varying effects of different types and experiences of maltreatment. For example, studies have found that juvenile and adult offending is more common in those individuals who have experienced more than one type of maltreatment (also referred to as multi-type maltreatment) and maltreatment that is recurrent (Hurren, Stewart, \& Dennison, 2017; Ryan \& Testa, 2005). Offending risk also appears to be related to the timing of maltreatment. Some studies have suggested that maltreatment that either starts or continues into adolescence is more consequential than maltreatment that is limited to the childhood years (Hurren et al., 2017; Malvaso, Delfabbro, \& Day, 2017b; Smith, Ireland, \& Thornberry, 2005), whereas others have asserted that childhood-limited maltreatment is also a critical factor in juvenile offending (Mersky, Topitzes, \& Reynolds, 2012). Links have also been drawn between type and timing of maltreatment and offense type, with studies finding that adolescent maltreatment, physical abuse and neglect are associated with violent crime (Maxfield \& Widom, 1996; Mersky \& Reynolds, 2007; Smith et al., 2005; Thornberry, Henry, Ireland, \& Smith, 2010).

Some young people whose maltreatment is particularly severe, and who are placed in out-of-home care $(\mathrm{OHC})$ as a result, might be especially at risk of engaging in violent crime (DeGue \& Widom, 2009; Lemmon, 2006). Although it is acknowledged that experiences prior to being placed (for example, abusive or neglectful treatment) are likely to influence these findings, the $\mathrm{OHC}$ experience itself might also exacerbate these early vulnerabilities. For example, being placed at an older age, in group homes or residential care facilities, and moving placements frequently have all been associated with problematic behavior (Baskin \& Sommers, 
2010; Jonson-Reid \& Barth, 2000; Widom, 1991). Only a handful of studies have considered how these variations in placement experiences relate specifically to violent offending. Lemmon (2006) reported that, although maltreatment recurrence predicted violent juvenile offending, this association was attenuated if the young person had subsequently been placed in foster care as a response to the abuse. Baskin and Sommers (2010) found that, although group home placement (or residential care) predicted both overall arrests and arrests for non-violent crimes, it was not associated with arrests for violent crimes. Finally, DeGue and Widom (2009) found that arrests for violent crimes among young people varied according to the type of placement they had experienced. For example, young people who had never been placed or who experienced foster care placements only were less likely to have been arrested for violent crimes in adolescence or adulthood. For young people who had been placed in non-foster care arrangements, or who had experienced a combination of foster and non-foster care placements, no associations with arrests for violent crime were found. Although these findings suggest that placement in foster care might be protective against violent offending, further exploration is needed to determine whether other placement factors, such as placement instability or duration of time in care, are associated with violent outcomes.

Given that not all individuals who experience maltreatment or who are placed in $\mathrm{OHC}$ go on to offend, and even fewer will commit violence offenses (Widom, 1991), it is likely that other individual characteristics will have discriminatory value. Yet only a few studies have examined the role of maltreatment in conjunction with other individual factors. For example, behavioral or emotional problems (e.g., conduct disorder, anger, aggression and poor social skills), factors relating to education (e.g., poor academic achievement or school engagement, impaired learning or reading abilities), mental health problems (e.g., depression, posttraumatic stress disorder and psychopathy), and substance misuse problems are all potential risk factors (Goodkind, Shook, Kim, Pohlig, \& Herring, 2012; Topitzes, Mersky, \& Reynolds, 2011; Verrecchia, Fetzer, Lemmon, \& Austin, 2010). 
Similarly, few studies have examined how other family background characteristics influence the maltreatment-violence link. Young people who are maltreated and those placed in $\mathrm{OHC}$ are likely to originate from complex families. Given that a history of poor family functioning has been consistently linked with youth crime (Sampson \& Laub, 2005; Stouthamer-Loeber, Loeber, Homish, \& Wei, 2001), it would be remiss to investigate the effects of maltreatment or $\mathrm{OHC}$ placement without reference to other underlying or pre-existing risk factors, such as the child's family background. A recent review of studies examining the broader maltreatment-offending association concluded that a multitude of familial factors play a role in mitigating or exacerbating risk (Malvaso et al., 2016). Parental separation or single parent families, parents with particular characteristics (e.g., lower levels of education and a history of substance abuse, mental health problems or criminality), and poor parent-child and peer relationships were all found to increase the risk of offending. Taking these factors into account might help us better understand the maltreatment-violence link.

Furthermore, relatively few studies have explored how gender and ethnicity might moderate the maltreatment-violence association while also controlling for other individual and social factors. This is an important consideration because it is likely that offending patterns are not uniform across gender and cultural subgroups (Broidy et al., 2015). An example of this type of research is a study by Goodkind et al. (2012), in which it was found that having received services related to substance abuse was associated with an increased likelihood of juvenile justice involvement for Caucasian boys, but a decreased likelihood for African American boys. Furthermore, Odgers et al. (2007) found that violent female offenders were more likely to have experienced violence themselves compared to non-violent offenders. Given the steady increases in female incarceration in more recent years (Kimonis et al., 2010), and that cultural minorities tend to be over-represented in groups of violent offenders, a more detailed analysis of the moderating effects of gender and cultural background is necessary. This is especially important within an Australian context in which Aboriginal and Torres Strait Islander children and young 
people continue to be over-represented in child protection and criminal justice services.

Although this is clearly also the case in other countries that have experienced colonization, there may be specific socio-political influences in Australia that influence levels of service involvement (e.g., Roediger et al., 2011). In addition, there may be important within-group differences in the experiences of Aboriginal and Torres Strait Islander families, given that there is no single culture and, indeed, over 600 distinctive cultural groups have been identified. Thus, while it is important from an Australian perspective to examine the impact of ethnicity on offending, particular care should be taken before generalizing any conclusions to other countries and cultural contexts.

\section{Theoretical underpinnings}

These empirical findings need to be understood in the context of broader psychological and criminological theories that attempt to explain why young people become involved in the criminal justice system. Although it is unlikely that any one theory holds all the answers, such frameworks can help to conceptualize and organize the thinking concerning the likely role of certain individual variables investigated in empirical research. Within this context, dynamic theories of crime, such as those arising from the developmental and life course (DLC) perspective, likely hold the most explanatory power. For example, two theoretical explanations have been advanced to elucidate why the timing of maltreatment is important for discriminating between offenders and non-offenders. The developmental psychopathology perspective suggests that maltreatment that occurs in early in childhood is critical because it disrupts ageappropriate development (Ireland, Smith, \& Thornberry, 2002). These experiences have been found to compromise attachment and self-regulation processes, which in turn are associated with poorer social outcomes such as aggression or association with deviant peers (Cicchetti \& Toth, 2016). On the other hand, the life course theory perspective emphasizes the role of more 
proximal experiences in the course of development (Sampson \& Laub, 1993), which has been used to explain the salience of maltreatment experienced in the adolescent years.

From a developmental victimology perspective, not only does the timing of various victimization experiences influence outcomes, but individual differences in responding to these experiences can also influence the way these risk factors translate into outcomes (Finkelhor \& Kendall-Tackett, 1997). A recent theoretical proposition, put forward in DeLisi and Vaughn's (2014) temperament-based theory of antisocial behavior, is that two constructs in particular effortful control and negative emotionality - can explain antisocial behavior across the life course. In terms of violent offending, negative emotions such as anger as well as a young person's ability to regulate such emotions, might be particularly influential. DeLisi and Vaughn (2014) suggest that poor anger control, and its behavioral manifestation in aggression, presents broader deficits in emotion regulation and is likely to be associated with a number of problems, including conduct disorder, peer rejection and lower social competence. Preliminary support for this theory has been demonstrated in a study of over 27,000 youth offenders, with findings indicating that recidivism rates are increased among those with lower levels of effortful control and higher negative emotionality (Baglivio, Wolff, DeLisi, Vaughn, \& Piquero, 2016). Similarly, one of the most prominent theories, Moffitt's (1993) developmental taxonomy, suggests that the more serious group of life course persistent offenders often suffer from a combination of neurocognitive and behavioral problems, including but not limited to intellectual disability, mental illness, and substance misuse. However, both DeLisi and Vaughn and Moffitt contend that that these problems are likely to arise in conjunction with inadequate and adverse rearing environments. These temperamental and behavioral traits in children and adolescents and parenting practices are thought to be transactional, that is, they interact to produce maladaptive outcomes.

Experiences of child maltreatment might underlie some of these behavioral traits observed in young people who offend. For example, Feiring, Miller-Johnson, and Cleland (2007) 
found that abuse-specific shame and self-blame attributions among victims of sexual abuse led to increased anger and, in turn, these factors were associated with increased delinquency. A number of studies have also linked experience of child physical abuse with perpetration of violent crime (Maxfield, Weiler, \& Widom, 2000; Smith et al., 2005), but neglect appears to also be emerging as an important predictor of violent crime (Malvaso et al., 2016). It might be that the trauma and stress associated with any experience of maltreatment, and its associated consequences of disrupted cognitive, educational and social development, is consequential in the etiology of violent behavior. These disruptions may then, for example, be reflected in the poor emotion regulation skills observed among violent offenders (Ford, Chapman, Connor, \& Cruise, 2012).

\section{The Present Study}

The primary aim of this study was to determine the unique contribution that maltreatment factors make to violent offending within what is already known to be a high risk population, that is, young people placed in secure care. Specifically, we sought to determine if the type, timing and recurrence of maltreatment related to youth violent crime convictions in the presence of other individual and social risk factors as delineated in the preceding literature review. These included OHC-related factors (including the type, timing and stability of placements), family and peer characteristics (including criminality, mental illness and substance use), and individual risk factors (including education, mental illness, substance abuse and behavioral problems).

Based on a subset of data drawn from a larger longitudinal project in which child protection and youth justice system information were linked using records from an Australian jurisdiction (South Australia), the present study includes data relevant to young people who entered secure care arrangements under Youth Justice supervision over a 17-year period and for whom detailed assessment information was available. There are two advantages in utilizing this particular sample: first, the potential maltreatment and placement histories of a group of highrisk offenders are captured, and second, the data includes not only official records of 
convictions but also assessment information relating to individual and social characteristics.

This self-report information has not previously been analyzed in combination with maltreatment and conviction records in South Australia. Although all of the data were extracted retrospectively based on a historical birth cohorts design, it does allow for a quasi-longitudinal analysis whereby the correct temporal order between onset maltreatment and violent convictions is maintained.

This study contributes to, and expands upon, the current knowledge base on the maltreatment-violence link in several ways. First, we explore the maltreatment-violence link in a sample of deep-end offenders, that is, those placed in secure care. Second, we were able to explore beyond the effects of composite measures of maltreatment by investigating the type, timing and recurrence of maltreatment. Third, we were able to determine how the type, timing and stability of $\mathrm{OHC}$ placements influence the risk for violent crime convictions. Fourth, we explore the unique contributions of maltreatment in the presence of a range of other known individual and social correlates of crimes. These included family- and peer-based risk factors, as well as the individuals' intellectual ability and education, substance abuse, mental illness, and behavioral problems. Finally, we explored factors that have a moderating effect on the maltreatment-violence association. In particular, we examined the roles of gender and cultural background in interaction with maltreatment and placement type, as well as how maltreatment type interacts with other individual risk factors (specifically anger and aggression) to influence the risk of violent crime conviction.

Based on the broader literature and the previous findings from analyses carried out on this dataset, two hypotheses were investigated: (1) Maltreatment risk factors, specifically type (physical abuse and neglect), persistent and recurrent maltreatment, would remain associated with violent convictions after controlling for family and peer characteristics and individual risk factors; and (2) Controlling for placement factors, specifically placement in residential care and placement instability, would attenuate the association between maltreatment risk factors and 
violent convictions. The minimal research on how interactions between gender, cultural background, and other factors influence the maltreatment-violence link makes it difficult to form hypotheses about these interactions. However, given that the broader maltreatmentoffending literature has demonstrated the moderating effects of gender, cultural background, substance abuse and behavioral problems, these analyses are included because they may contribute to further refinement of knowledge in the area of violent offending.

\section{Method}

The present study utilized self-report data for 1,819 young people who entered secure care arrangements under Youth Justice supervision in South Australia between 1995 and 2012. Individual and social measures were drawn from a standardized assessment instrument known as the Secure Care Psychosocial Screening (SECAPS; Putnins, 1999). SECAPS was used by psychologists and youth workers to collate client background information on a variety of factors relating to criminogenic need. If a young person was assessed more than once, the individual's first assessment was used in this study. The dataset was also linked with official records of youth crime convictions from age 10 to 18 and official child protection records (if any) for each individual prior to the age of 18 . Therefore, our sample includes complete convictions and child protection records for all individuals up to age 18. Child protection records included in this study were: 1) All records of notifications and substantiations for four types of child maltreatment (physical, sexual and emotional abuse, and neglect); and 2) Records of out-ofhome care $(\mathrm{OHC})$ placements (including type of placement, number of placements, duration of time in $\mathrm{OHC}$, and age at time of first placement). The data were linked using a common numerical identifier. To ensure the correct temporal order between associations, 226 young people were excluded because their age at first conviction was equal to or less than their age at first maltreatment substantiation. For further information about the larger data linkage study 
from which this sample was drawn, see (authors names left out for the purposes of blind review).

\section{Measures}

The dependent variable in this study was represented by a dichotomous indicator which differentiated young offenders with convictions for at least one violent crime and those without any violent crime convictions prior to the age of 18 . Violent convictions were counted if records indicated a conviction for homicide, assault, sexual assault or robbery, and were included if the incident was proven or agreed to, but not officially recorded as a conviction. Proven or agreed offenses are offenses that have been legally proven but the young person does not receive a formal conviction and reflects the emphasis in South Australia on diversion through informal and formal cautioning and group conference options (as stipulated in the Young Offenders Act, 1993). Matters that had been dismissed, not proceeded with, or committed to trial in which the defendant was subsequently found not guilty were not counted.

Independent variables included self-reported and assessed demographic, individual and social measures as well as official records of maltreatment and placement in OHC. Two demographic variables were included: gender was represented by a dichotomous variable differentiating males from females; and cultural background by a dichotomous variable differentiating between Indigenous and non-Indigenous young people. ${ }^{1}$

Maltreatment variables included substantiated incidents of neglect or physical, sexual or emotional abuse. Each type of maltreatment was dichotomized to differentiate between young people for whom a substantiation for each type had ever been made or not. These groupings are not mutually exclusive because most young people had experienced more than one type of abuse and therefore were included in each respective group. Maltreatment type was also used to

\footnotetext{
${ }^{1}$ As noted above, there are distinctive cultural differences between Aboriginal and Torres Strait Islander communities which may be overlooked by this method of classifying ethnicity. However, more detailed cultural data were not available and are not routinely collected by government agencies in Australia.
} 
create a multi-type maltreatment variable (the experience of two or more types of abuse or neglect). Number of substantiations (recurrence) was used as a continuous measure. Age at substantiation was used to create three groups reflecting the timing of maltreatment: childlimited maltreatment (young people for whom notifications and substantiations were made exclusively prior to the age of 11); adolescent-limited maltreatment (notifications and substantiations made exclusively after the age of 12); and persistent maltreatment (notifications and substantiations made both prior to and after the age of 12).

Placement in out-of-home care was considered only among individuals for whom maltreatment substantiations had been made prior to placement (those entering care from pathways other than child protection - for example because they were orphaned or their parents could no longer or were unwilling to care for them due to mental health or behavioral problems - were excluded because the focus is on the link between maltreatment and offending). Placement type included three dichotomous variables differentiating between those who had ever experienced placements in foster care, residential care, and kinship care. These groupings are not mutually exclusive as many young people experience more than one type of placement. Age at first placement is the age (in years) at which the young person experienced their first OHC placement. Placement instability represents the total number of different placements experienced. Respite placements were not included in this count.

Individual and social risk factors were broken down into several groups. Family and peer risk indicators included several dichotomous variables: parental death (genetic mother or father has passed away); parental separation (had parents who were not living together); family history of crime (had a parent or sibling who is or has been in trouble with the law); family history of substance abuse (had a parent or sibling who had or has substance use problems); household conflict (lived in households characterized by lots of fights/arguments); motherchild/father-child/stepparent-child relationship (had poor relationships with their mother/father or with a stepparents); peer criminality (association with peers who are in trouble with the law). 
Individual risk factors were further broken down into the following subcategories: intelligence and education; substance use; mental health problems; and behavior problems. Intelligence and education included the following dichotomized variables: intellectual ability (scores above borderline on the Raven's progressive matrices; Raven \& Court, 1998); school problems (had dropped out or been suspended/expelled/excluded); reading difficulties (scores below 10 on the Australian normed Concision Word Reading Test; Andrews, 1974).

Substance use included the following dichotomized variables: overall substance use (had used alcohol, marijuana, hallucinogens, sedatives, narcotics, stimulants, inhalants or other in the last four weeks prior to assessment); problematic alcohol use (consumed three or more drinks on days when drinking); and problematic marijuana use (had one or more joints on days when using marijuana). Problematic alcohol and marijuana use were operationalized in accordance with Australia's National Health and Medical Research Council (NHMRC) guidelines.

Mental health problems included two dichotomous measures of depressive mood states. Chronic depressive mood was endorsed if the young person selected 3 or below on a 10-point scale (where $0=$ worst feeling possible/very depressed and $10=$ best feeling possible/very happy) and indicated they had been feeling this way for weeks or longer. Two measures relating to suicide were included: suicide ideation was endorsed if a young person reported having thoughts of committing suicide in the past week, and suicide attempt was endorsed if a young person reported having tried to kill themself in the past.

Behavior problems included dichotomous measures of anger and aggression. Anger was endorsed if a young person reported having a bad temper. Aggression was endorsed if a young person reported getting into fights a couple of times a year or more frequently.

\section{Data Analysis Procedures}


Data analysis was conducted in several phases. First, a descriptive overview of the sample is presented and the overall likelihood of maltreated young people having violent crime convictions was determined using chi-square tests of independence. Second, a set of comparative analyses of independent demographic, individual, social, maltreatment and placement variables was undertaken to determine whether violent offenders differed from nonviolent offenders. These analyses are not presented in this paper but have been included as part of the online supplementary material. Third, a number of interaction terms were created using gender, cultural background, maltreatment type and other variables in order to examine any moderating effects on violent offending convictions. Finally, variables found to be significant in the second and third phases were entered into a series of logistic regressions in order to model the best overall predictors of violent convictions. Maltreatment and placement variables were entered first, followed by demographic and background factors, individual factors and finally interaction terms.

\section{Results}

Summary statistics for the sample of offenders are reported in Table 1, as well as comparisons between males and females, and Indigenous and non-Indigenous offenders, on the variables of interest. Although male offenders outnumbered female offenders by more than five to one, a slightly higher proportion of females and Indigenous young people had convictions for violent crimes compared to males and non-Indigenous offenders. A number of differences were found between males and females, and Indigenous and non-Indigenous offenders, in terms of family and peer, individual, maltreatment and placement risk indicators, and these differences were used to inform the subsequent moderation analysis.

\section{Moderation Analysis}


A number of interaction terms informed by the preceding literature review were tested to determine whether associations between maltreatment and violent crime convictions were moderated by gender, cultural background or other factors. Interactions between gender and placement in foster and residential care were found, Wald $(1)=7.54, p<.01$, and Wald $(1)=$ $5.57, p<.01$, respectively. Placement in foster and residential care was associated with 3.02 and 2.90 times greater likelihoods of violent convictions for males; however, these variables were not significantly associated with convictions for females. Interactions between maltreatment subtypes and individual risk factors were tested and three significant interactions were found: child physical abuse (CPA) by problematic alcohol use (Wald $(1)=5.75, p<.05)$, neglect by problematic alcohol use (Wald $(1)=4.22, p<.05)$, and neglect by aggression (Wald $(1)=4.02$, $p<.05)$. Those with alcohol problems who had not experienced CPA or neglect had a reduced likelihood of violent convictions ( $26 \%$ and $22 \%$, respectively). Among those who had not experienced neglect, aggression was associated with a 57\% increased likelihood of violent convictions; however, for those who had experienced neglect, aggression was associated with a 2.69 times greater likelihood of violent convictions. Finally, the interaction between gender and anger approached significance (Wald $(1)=3.17, p=.07$ ), with anger associated with a $44 \%$ increased likelihood of violent convictions for males, but not significantly associated with the outcome for females.

\section{Logistic Regression}

Logistic regression analysis was used to examine predictors of violent convictions. The modeled factors were those found to differ significantly at the bivariate level between young offenders with and without violent convictions (see supplementary online material). Five models were fitted: the first included variables relating to maltreatment experiences; in the second, placement in out-of-home care $(\mathrm{OHC})$ variables were added; demographic and family/peer risk indicators were added to the third; individual included risk factors were added 
to the fourth; and finally, significant interaction terms were added to the fifth model. However, after inspection of multicollinearity diagnostics (eigenvalues and variance proportions) a high proportion of shared variance between child physical abuse, neglect, multi-type maltreatment and recurrence was found. Correlated predictors in regression models are likely in social science research (Ludlow \& Klein, 2014) and one solution is to omit one of the co-linear variables; however, there are no statistical procedures for knowing which variable to omit (Field, 2009). Although we applied criteria endorsed by Field (2009) for assessing collinearity (tolerance scores of below 0.1 and variance inflation factors of 10 or more), it is possible that more subtle forms of collinearity remained. Indeed, there is some disagreement about score cut offs, with others suggesting that even small correlations between independent predictors can cause collinearity problems (Myers, 1990; Stine, 1995), and thus more stringent criteria need to be applied. Another issue is that when too many variables are entered into a regression model, significant effects might be masked. We addressed these problems in two ways. First, the aforementioned variables with high proportions of shared variance were entered into the models separately. Only CPA and neglect were significant predictors of violent convictions after Model 1, and because there was little change in the subsequent models when either CPA or neglect were entered, Table 2 displays the results in which only the former was added. Second, to reduce the number of variables entered into the final models, only variables with a variance inflation score lower than three and variables and interactions that were significant at the $p<.01$ level in the bivariate and interaction analyses were entered.

Data for 1,819 young offenders were available for analysis. As shown by the progressive reduction in the -2 log-likelihood ratio across the five models (Table 2), the addition of variables greatly improved the predictive power of the model. Consistent with Hypothesis 1, persistent maltreatment remained a predictor of violent convictions in each model (and was associated with a 33\% increased likelihood of convictions in the final model). Physical abuse and neglect (not shown) were both marginally associated with violent 
convictions in Model 1; however, these associations did not remain significant after the addition of the placement variables in Model 2 (as consistent with Hypothesis 2).

Placement in foster care was also marginally associated with the outcome until the addition of demographic and background factors in Model 3; however, placement in residential care retained its marginal significance in predicting the outcome until the final model, indicating that maltreated individuals who had been subsequently placed in residential care were between $70 \%$ and $71 \%$ more likely to be convicted of a violent crime. Indigenous young people were also more likely to convicted, with a $51 \%$ increase in the likelihood of violent convictions for these individuals in the final model. Young people who came from homes characterized by conflict were $42 \%$ more likely to be convicted of a violent crime, although this association only approached significance in Models 4 and 5 after individual and interaction variables were added to the models.

The strongest predictors of violent convictions were the individual level risk factors of anger and aggression. In the final model, young people who had problems with anger or who were aggressive were $41 \%$ and $66 \%$ more likely to have convictions for violent crimes, respectively. In the final model, males were also found to have a $76 \%$ increased likelihood of violent convictions, although the interaction terms were not significantly associated with the outcome. Although it was hypothesized that maltreatment risk factors would remain associated with violent convictions after controlling for other individual and social risk factors, only persistent maltreatment remained a significant predictor and the subsequent addition of variables attenuated this effect. Although both the foster and residential care variables were no longer significant in the final model, further inspection of the regression table indicated possible multi-collinearity problems. For example, the odds ratios for these variables were still quite large; however, the standard errors ( 0.91 and 0.97 , respectively) were also large. This could be due to the small number of offenders with maltreatment substantiations who were subsequently placed into these different care arrangements. 


\section{DISCUSSION}

The principal aim of this study was to examine the extent to which maltreatment experiences were associated with violent crime convictions after controlling for other individual and social risk factors in a sample of youth detained in secure care. Specifically, we aimed to determine the extent to which variations in maltreatment experiences were associated with violent convictions after controlling for a range of other known correlates. Two hypotheses were tested: first, that child physical abuse (CPA), neglect, persistent and recurrent maltreated would remain associated with violent convictions after controlling for other individual and social risk factors, and second, that controlling for placement in residential care and placement instability would attenuate the association between maltreatment and violent convictions. Only persistent maltreatment was a consistent predictor across all models, with the initial effects of CPA and neglect being reduced after controlling for placement variables. Placement in foster care and residential care were also significant predictors of violent crimes until other family background and individual risk factors were added to the models. Consistent with our second hypothesis, controlling for placement factors attenuated the associations between CPA and neglect and violent convictions; however, persistent maltreatment remained strongly associated with the outcome. Therefore, partial support for our hypotheses was demonstrated.

Although the addition of family, peer and other individual risk indicators to the models predicting violent convictions were important, and attenuated the positive association found between maltreatment and placement variables with violent offending, experiencing maltreatment that persisted from childhood through to adolescence remained a strong indicator of subsequent violent convictions. These findings reflect those obtained in other studies which have also found persistent maltreatment to be consequential in the development of both violent criminal behavior (Smith et al., 2005) and offending more generally (Malvaso et al., 2017b; Stewart, Livingston, \& Dennison, 2008). 
Developmental and life-course (DLC) explanations concerning the consequences of timing in maltreatment experiences have been advanced (Smith et al., 2005), with developmental theories positing that maltreatment that occurs in childhood is consequential because it disrupts age-appropriate development (Cicchetti \& Toth, 1995), whereas maltreatment occurring in adolescence has a more proximate effect on the development of offending behavior (Sampson \& Laub, 2005). Experiencing maltreatment in both childhood and adolescence would arguably have the most adverse influence on behavior; however, the reason for this association needs to be examined in more depth. For example, victims of persistent maltreatment are likely to have had extended exposure not only to maltreatment, but also to other adverse family circumstances that have influenced the development of antisocial behaviors (Malvaso \& Delfabbro, 2015). This might be particularly relevant in cases of neglect, which often involve parents who are engaged in criminal activity or who have drug and alcohol problems. Indeed, there is evidence that parental criminality is associated with aggression in their offspring (Tzoumakis, Lussier, \& Corrado, 2014). As suggested by social learning theory, the modeling and reinforcement of these behaviors by young people in these circumstances might explain the increased risk for violent convictions among victims of persistent maltreatment. Indeed, exposure to household conflict was found to be marginally associated with an increased likelihood of violent crime convictions.

It is well-established that maltreatment results in neurological and psychological changes in the developing child (Mayes, 1999; Pardini \& Frick, 2013; Vig, Chinitz, \& Sbulman, 2005). Social-cognitive studies have demonstrated how individuals exposed to trauma and abuse develop a propensity to perceive even trivial situations as threatening, activating anger and fight reactions. In these situations, biologically predisposed survival responses or attack behaviors are triggered, and in the longer term, these individuals are less able to regulate their emotions (in particular anger; Pardini \& Frick, 2013) and are more likely to act aggressively. Indeed, anger and aggression were strongly associated with violent crime convictions in this study. This finding adds further credence to DeLisi and Vaughn's (2014) temperament based theory that 
negative emotionality is an important construct in the development of antisocial behavior and supports the idea that negative emotionality, as a dynamic risk factor for offending, can be targeted for treatment (Day, 2009). Developing young offenders' self-regulation skills is one possible way to reduce these negative emotions and can be especially relevant in secure custody settings because anger is also strongly associated with physical aggression towards others in these environments (including both staff and other detainees; DeLisi \& Vaughn, 2014).

Aggression also moderated the association between neglect and violent convictions. Although this interaction was not significant in the final multivariate analysis, it is still an interesting finding that warrants further discussion. From a social learning perspective, studies have demonstrated that violent or abusive parental behavior is modeled by children and results in angry and aggressive emotional expression (Toth et al., 2011). In terms of neglect, however, the explanation is likely to be more complex. It could be that these young people might not have been afforded sufficient opportunities for acquiring emotional learning strategies, such as decreased opportunities in decoding emotional signals. Under stress, it might be difficult for victims of neglect to recognize social cues enacted by others and could facilitate inappropriate responses, such as anger and aggression (Pardini \& Frick, 2013). It is also acknowledged that neglect often co-occurs with other forms of abuse, especially CPA (Knutson, DeGarmo, \& Reid, 2004). As our maltreatment categories were not mutually exclusive, co-occurrence of abuse types might also explain the increased association between neglect and aggression.

Another potentially related finding was that, compared to offenders who had experienced CPA or neglect, those without these experiences but who had problems with alcohol had a reduced likelihood of violent convictions. It might be that alcohol use plays a unique role in the violent offending behavior of maltreatment victims, and this finding could also be related to the increased aggression found among victims of neglect. For example, Widom, Schuck, and White (2006) found that maltreatment was indirectly associated with alcohol use through early aggressive behaviors which was, in turn, associated with juvenile and adult violent arrests 
among males. In the female model, however, maltreatment was directly associated with alcohol problems, which in turn was associated with violent arrests. Both alcohol use and aggressive behaviors have been identified as coping strategies adopted as a response to trauma (Schuck \& Widom, 2005; Pardini \& Frick, 2013), and, as well as being more broadly associated with violence, appear to be mechanisms that are useful in explaining the higher risk of violence perpetration among victims of maltreatment. However, there might be a more proximate association between alcohol use as a coping mechanism for female victims of maltreatment, in contrast to a more distal association through aggression for male victims. Indeed, we found some evidence that anger moderated the association between gender and violent convictions, with anger increasing the likelihood of violent convictions for males but not for females.

Although studies have explored the role of placement in $\mathrm{OHC}$ with offending outcomes more generally, fewer studies have considered the relationship with violent outcomes. We found that males placed in both foster and residential care had two-to-three times the odds of violent convictions, although these interactions were not significant in the final analyses. Main effects for placement in foster and residential care were also found. These findings are somewhat novel in that previous research has found that group home placement was not associated with violent arrests (Baskin \& Sommers, 2010), and that placement in foster care was associated with a reduced likelihood of violent arrests (DeGue \& Widom, 2009). One point of difference between these and the present study is that the maltreatment-violence link was explored in a sample of deep-end offenders. It might be that placement is associated with more serious and chronic offending, as found in The Incarcerated Serious and Violent Young Offender study (Yang et al., 2017).

With respect to gender differences in the placement-offending link more broadly, the findings have been mixed (Goodkind et al., 2012; Ryan et al., 2010). Although placement appears to be more consequential for violent offending among boys in this study, the potentially negative or protective effects for females need further consideration. Consistent with emerging 
trends in the international literature (Goodkind et al., 2012), two other Australian studies have found that placement in residential care is more consequential in the offending behavior of females (Malvaso \& Delfabbro, 2015; Malvaso, Delfabbro, \& Day, 2017a); however, the present study suggests that these associations do not necessarily help to discriminate between female offenders with and without violent crime convictions. It might be that placement plays a role in the initiation of offending for females, but is not related to the perpetration of violent crime. It has been suggested that female offending might be better characterized as a survival or defense strategy used to cope in abusive environments as opposed to being intrinsically antisocial and is reflected in their tendency to be arrested for non-violent crimes (e.g., absconding from placements, substance use and prostitution; Kerig \& Becker, 2015). Furthermore, although overall male offenders outnumbered female offenders by more than five to one, of the much smaller number of females with convictions a slightly higher proportion had convictions for violent offenses compared to males. This is an interesting finding and one interpretation is that criminal justice official may respond more harshly to female violence compared to male violence. For example, fighting among males might be considered to be normative than fighting among females. If this type of behavior, and violence more generally, is viewed as more serious when committed by females, they might be more likely to be treated punitively or sentenced to time in secure detention. Alternatively, authorities might be less willing to convict and incarcerate females compared to males, so that when females are convicted, there might be a tendency for them to be convicted of more serious (i.e., violent) crimes.

\section{Implications for future research, policy and practice}

Juvenile justice service responses usually do not recognize maltreatment, or the consequences of maltreatment experiences, as a primary focus for service intervention (van der Put \& de Ruiter, 2016). The findings from this study highlight the potential for the development 
of service frameworks that integrate the consequences of maltreatment and other criminogenic needs in responding to violent offending. Overall, persistent maltreatment is emerging as an important predictor of criminal behavior, and the findings of this study strengthen the need for the assessment of, and integration of services that respond to, maltreatment among serious youth offenders. Furthermore, there was some evidence that anger, aggression and problematic alcohol use played a moderating role in the association between maltreatment and violence. Interventions targeting these characteristics might be broadly useful for violent offenders, but specifically for offenders with histories of maltreatment. Further exploration is needed to assess whether angry or aggressive responses in violent offenders differ in any way between those who have experienced maltreatment and those who have not (e.g., specific triggers or different types of violent acts). Talking about maltreatment and allowing it to be processed might lead to a better understanding of the developmental precursors or anger-related aggression, which in turn could lead to more effective treatment.

Consistent with DLC theories of offending, it is clear that violent behavior is influenced by a range of risk factors from multiple ecological levels and these influences can vary across the course of development (Cicchetti \& Toth, 2016; Piquero, 2015). Given the considerable amount of social policy, services and practice that occurs in the context of both the criminal justice and welfare systems, and not always with a necessarily strong appreciation of bidirectional influences of one system on the other, it is important to translate these theoretical and empirical findings into practice. For those working in youth justice and attempting to understand differences within their client population, the focus should be on understanding how maltreatment and trauma influences behavior. On the other hand, those working in child protection may be predominantly focused on mitigating the consequences of maltreatment and preventing of high-risk behavior such as offending. Interventions in both areas need to take into account not only the multiple determinants of criminal behavior but also acknowledge that the determinants might differ for males and females and ethnic minorities and majorities. 
Understanding gender and ethnic differences in the study and treatment of violence is not only important for deepening our understanding of potentially distinct pathways, but it is also important for the development of theory. As pointed out by Piquero (2015) and Broidy et al. (2015), theoretical perspectives on the roles of race and ethnicity are particularly underdeveloped and DLC theories should be expanded to focus on these diverse pathways. More detailed explorations of differences in the longitudinal patterns of offending in these groups and needed in order to confirm or further understand why individuals from minority ethnic groups are over-represented in offending and crime statistics (e.g., differential enforcement or the tendency of police to patrol certain areas or to stop or arrest individuals of color). Our study provided further insight into these differences and support for the need for integration of these gender and ethnic specific pathways into DLC theories. However, there is a need for further research to explore and compare the pathways that potentially exist between Aboriginal and Torres Strait Islander youth in Australia and minority groups in other countries, as well as differences between Aboriginal and Torres Strait cultures.

\section{Limitations and future research}

Although this study identifies a number of important mechanisms that might help to explain the link between maltreatment and violent offending, several caveats need to be mentioned. First, the study design is not prospective and does not include comparison groups of either non-maltreated individuals or individuals who have not been involved in offending. Despite using a quasi-longitudinal design in which the correct temporal order between onset of maltreatment and convictions was maintained, causal inferences are limited and further longitudinal work is needed to replicate findings. Although temporal order in terms of onset of maltreatment preceding violent convictions, it is acknowledged that associations between maltreatment and violence was not straightforward when operationalizing some variables. For example, in the case of persistent maltreatment, although we ensured that the onset of 
maltreatment preceded the first violent conviction, it is probable that some maltreatment has taken place after some violence. Furthermore, the use of official records means that there may be a margin of error when examining timing because we are relying on known and recorded instances of maltreatment and offending only. Second, the issue of multi-collinearity in the regression analyses might have affected model estimates, resulting in less reliable findings. However, we applied more stringent criteria to assess these problems and examined correlated predictors separately to aid interpretation. Finally, although moderating effects were explored in this study, it is possible that mediation could further elucidate associations between maltreatment, other risk factors, and violent offending. Future research could endeavor to explore more complex models using structural equation modeling (SEM) in order to ascertain direct and indirect pathways. For example, Wolff and Baglivio (2017) used SEM to demonstrate that negative emotionality was a key mechanism in the pathway through which ACEs affect youth offending and accounted for almost 50 per cent of the total effects of ACEs on recidivism. Analyses could also be broken down by gender and cultural background to further explore distinct pathways to crime for these groups.

A further consideration in future research is the use of official records of maltreatment in contrast with self-reported maltreatment. The majority of longitudinal studies examining the maltreatment-offending association have used official records of abuse and neglect (Malvaso, Delfabbro, \& Day, 2015). Limited to information collected by official agencies, these studies might thus underestimate associations with offending because not all children and young people who experience maltreatment are notified. Others have argued that studies which limit their examination to cases in which maltreatment has been substantiated or verified may also exaggerate the size of the association by focusing only on outcomes of those who have been severely maltreated (Lansford et al., 2007). Another significant issue in the use of official records is the possibility of cultural reporting biases. It might be that Aboriginal children are more likely to come to the attention of official agencies due to over-surveillance issues. Despite 
these limitations, Smith et al. (2008) concluded that the key advantages of using official records of maltreatment is that because the date of the incident or incidents are known, this information can be used to ensure the correct temporal order between associations.

In contrast to the use of official records of maltreatment, the growing body of research on ACEs and offending is predominantly based on self-report measures and has demonstrated the utility of these measures in capturing a broader inventory of experiences. Despite this, there are also a number of biases associated with self-report measures of maltreatment. These measures are more prone error because they include a level of subjectivity (for example, they can be affected by the mood of the reporter) and may introduce biases associated with recall (for example, memory problems associated with ageing or infantile amnesia) and social desirability.

A handful of studies have used both official and self-reported measures of maltreatment in the same study (e.g., Baglivio et al., 2016) and a few have examined the concordance of the two measures. For example, while Smith, Ireland, Thornberry, and Elwyn (2008) found moderate concordance between official records and self-reported maltreatment, they also found that the prevalence of maltreatment was higher in self-report measures. However, Brown et al. (1998) found that only 17 per cent of self-reported maltreatment was confirmed in official records, while 60 per cent of official records were not self-reported in adulthood. Others have demonstrated variations according to gender and the type of abuse, for example, sexual abuse has been found to be especially underreported by adults (Widom \& Morris, 1997). It is clear that, overall, each approach has its strengths and weaknesses and, where possible, researchers are encouraged to use both official records and self-reported measures of maltreatment so that the two can be compared and contrasted.

Although this study contributes to the growing body of literature on the maltreatmentoffending association by identifying risk factors using data drawn from a population that has yet to be studied, research is needed to further explicate the underlying processes or mechanisms responsible for transforming risk into outcomes. For example, how is persistent maltreatment 
related to exposure to other adverse experiences (e.g., parental substance misuse or criminality) or other types of victimization (e.g., witnessing domestic violence or bullying)? This is in line with research attempting to elucidate the consequences of poly-victimization (Finkelhor, Ormrod, \& Turner, 2007), and is consistent with a developmental victimology perspective that emphasizes the role of many forms of victimization and how these experiences, and responses to these experiences, change over the course of development (Finkelhor \& Kendall-Tackett, 1997). Although this study focused on maltreatment, viewing victimization more broadly within an integrated developmental framework might provide further insight into how an individual reacts to these experiences at different stages of their development.

In conclusion, a number of risk factors contribute to the risk of violent crime convictions in youth but many of these are insufficient to stand alone as explanations of violent crime. In addition to other family background and individual risk factors, persistent maltreatment appears to contribute to youth violent offending. Since it has been established that there is continuity from adolescent to adult offending, and that both violent offenders and victims of maltreatment are more likely to start their criminal careers earlier (further increasing their risk of perpetration of violent crimes into adulthood), early intervention and prevention efforts targeting both maltreatment and juvenile offending appear necessary. It is clear that collaborative and integrated responses from child protection and juvenile justice are needed. Harnessing expertise from both areas and working with the young people and their families appears to be a promising and economically justifiable approach to prevention before these behaviors become more entrenched in adulthood.

Acknowledgements: This work was made possible by a collaboration between the University of Adelaide and two South Australian government departments: The Department for Child Protection and Youth Justice (Department for Communities and Social Inclusion). 


\section{References}

Andrews, R. J. (1974). Concise Word Reading Tests. Brisbane, Australia: Teaching and Testing Resources.

Baglivio, M. T., \& Epps, N. (2015). The Interrelatedness of Adverse Childhood Experiences Among High-Risk Juvenile Offenders. Youth Violence and Juvenile Justice, 14(3), 179-198. doi: 10.1177/1541204014566286

Baglivio, M. T., Wolff, K. T., DeLisi, M., Vaughn, M. G., \& Piquero, A. R. (2016). Effortful control, negative emotionality, and juvenile recidivism: an empirical test of DeLisi and Vaughn's temperament-based theory of antisocial behavior. The Journal of Forensic Psychiatry \& Psychology, 27(3), 376-403. doi: 10.1080/14789949.2016.1145720

Baglivio, M. T., Wolff, K. T., Piquero, A. R., Bilchik, S., Jackowski, K., Greenwald, M. A., \& Epps, N. (2016). Maltreatment, child welfare, and recidivism in a sample of deep-end crossover youth. Journal of Youth \& Adolescence, 45(4), 625-654.

Baskin, D. R., \& Sommers, I. (2010). Child Maltreatment, Placement Strategies, and Delinquency. American Journal of Criminal Justice, 36(2), 106-119. doi: 10.1007/s12103-010-9088-9

Broidy, L. M., Stewart, A. L., Thompson, C. M., Chrzanowski, A., Allard, T., \& Dennison, S. M. (2015). Life course offending pathways across gender and race/ethnicity. Journal of Developmental and Life-Course Criminology, 1(2), 118149. doi: $10.1007 / \mathrm{s} 40865-015-0008-\mathrm{z}$

Cicchetti, D., \& Toth, S. L. (1995). A developmental psychopathology perspective on child abuse and neglect. Journal of the American Academy of Child \& Adolescent Psychiatry, 34(5), 541-565.

Cicchetti, D., \& Toth, S. L. (2016). Child maltreatment and developmental psychopathology: A multilevel perspective. In D. Cicchetti (Ed.), Developmental psychopathology, maladaptation and psychopathology. New York: Wiley.

Day, A. (2009). Offender emotion and self-regulation: implications for offender rehabilitation programming. Psychology, Crime \& Law, 15(2-3), 119-130. doi: $10.1080 / 10683160802190848$

DeGue, S., \& Widom, C. S. (2009). Does out-of-home placement mediate the relationship between child maltreatment and adult criminality? Child Maltreatment, 14(4), 344-355. doi: 10.1177/1077559509332264

DeLisi, M., \& Vaughn, M. G. (2014). Foundation for a temperament-based theory of antisocial behavior and criminal justice system involvement. Journal of Criminal Justice, 42(1), 10-25. doi: 10.1016/j.jcrimjus.2013.11.001

Feiring, C., Miller-Johnson, S., \& Cleland, C. M. (2007). Potential pathways from stigmatization and internalizing symptoms to delinquency in sexually abused youth. Child Maltreatment, 12(3), 220-232. doi: 10.1177/1077559507301840

Field, A. (2009). Discovering statistics using SPSS. London: Sage Publications.

Finkelhor, D., \& Kendall-Tackett, K. (1997). A developmental perspective on the childhood impact of crime, abuse, and violent victimization. In D. Cicchetti \& S. L. Toth (Eds.), Developmental perspectives on trauma: Theory, research and intervention (pp. 1-32). New York: University of Rochester Press.

Finkelhor, D., Ormrod, R., \& Turner, H. (2007). Poly-victimization: A neglected component in child victimization trauma. Child Abuse \& Neglect, 31, 7-26.

Ford, J. D., Chapman, J., Connor, D. F., \& Cruise, K. R. (2012). Complex trauma and aggression in secure juvenile justice settings. Criminal Justice and Behavior, 39(6), 694-724.

Goodkind, S., Shook, J. J., Kim, K. H., Pohlig, R. T., \& Herring, D. J. (2012). From child welfare to juvenile justice: Race, gender, and system experiences. Youth Violence and Juvenile Justice. doi: 10.1177/1541204012463409 
Halemba, G. J., \& Lord, B. D. (2005). Effectively intervening with dual jurisdiction youth in Ohio. Children, Families and the Courts, Ohio Bulletin, 2, 1-28.

Halemba, G. J., Siegel, G. L., Lord, R. D., \& Zawacki, S. (2004). Arizona dual jurisdiction study: Final report. Pittsburgh, PA: National Center for Juvenile Justice.

Huang, H., Ryan, J. P., Sappleton, A., \& Chiu, Y.-L. (2015). Crossover youth post arrest: Placement status and recidivism. Children and Youth Services Review, 57, 193200. doi: 10.1016/j.childyouth.2015.08.015

Hurren, E., Stewart, A., \& Dennison, S. (2017). Transitions and turning points revisited: A replication to explore child maltreatment and youth offending links within and across Australian cohorts. Child Abuse \& Neglect, 65, 24-36. doi: 10.1016/j.chiabu.2017.01.002

Ireland, T. O., Smith, C. A., \& Thornberry, T. P. (2002). Developmental issues in the impact of child maltreatment on later delinquency and drug use. Criminology, 40(2), 359-399.

Jonson-Reid, M., \& Barth, R. P. (2000). From placement to prison: The path to adolescent incarceration from child welfare supervised foster or group care. Children and Youth Services Review, 22(7), 493-516.

Kerig, P. K., \& Becker, S. P. (2015). Early abuse and neglect as risk factors for the development of criminal and antisocial behavior. In J. Morisot \& L. Kazemian (Eds.), The development of delinquent and antisocial behavior (pp. 181-199). Switzerland: Springer International Publishing.

Kimonis, E. R., Skeem, J. L., Edens, J. F., Douglas, K. S., Lilienfeld, S. O., \& Poythress, N. G. (2010). Suicidal and criminal behavior among female offenders: The role of abuse and psychopathology. Journal of Personality Disorders, 24(5), 581-609.

Knutson, J. F., DeGarmo, D. S., \& Reid, J. B. (2004). Social disadvantage and neglectful parenting as precursors to the development of antisocial and aggressive child behavior: Testing a theoretical model. Aggressive Behavior, 30(3), 187-205. doi: 10.1002/ab.20016

Lansford, J. E., Miller-Johnson, S., Berlin, L. J., Dodge, K. A., Bates, J. E., \& Pettit, G. S. (2007). Early physical abuse and later violent delinquency: A prospective longitudinal study. Child Maltreatment, 12(3), 233-245. doi: $10.1177 / 1077559507301841$

Lemmon, J. H. (2006). The effects of maltreatment recurrence and child welfare services on dimensions of delinquency. Criminal Justice Review, 31(1), 5-32. doi: $10.1177 / 0734016806287945$

Ludlow, L., \& Klein, K. (2014). Suppressor variables: The difference between 'is' versus 'acting as'. Journal of Statistics Education, 22(2), 1-28.

Malvaso, C. G., \& Delfabbro, P. (2015). Offending behaviour among young people with complex needs in the Australian out-of-home care system. Journal of Child and Family Studies, 24(12), 3561-3569.

Malvaso, C. G., Delfabbro, P., \& Day, A. (2015). The maltreatment-offending association: A systematic review of the methodological features of prospective and longitudinal studies. Trauma, Violence, \& Abuse, 1-15. doi: $10.1177 / 1524838015620820$

Malvaso, C. G., Delfabbro, P., \& Day, A. (2016). Risk factors that influence the maltreatment-offending association: A systematic review of prospective and longitudinal studies. Aggression \& Violent Behavior, 1-15. doi: 10.1016/j.avb.2016.06.006

Malvaso, C. G., Delfabbro, P., \& Day, A. (2017a). Child maltreatment and criminal convictions in youth: The role of gender, ethnicity and placement experiences in 
an Australian population. Children and Youth Services Review, 73, 57-65. doi: 10.1016/j.childyouth.2016.12.001

Malvaso, C. G., Delfabbro, P., \& Day, A. (2017b). The child protection and juvenile justice nexus in Australia: A longitudinal examination of the relationship between maltreatment and offending. Child Abuse \& Neglect, 64, 32-46. doi: 10.1016/j.chiabu.2016.11.028

Maxfield, M. G., Weiler, B. L., \& Widom, C. S. (2000). Comparing self-reports and official records of arrests. Journal of Quantitative Criminology, 16(1), 87-110.

Maxfield, M. G., \& Widom, C. S. (1996). The cycle of violence: Revisited 6 years later. Archives of Pediatrics and Adolescent Medicine, 150(4), 390-395.

Mayes, L. C. (1999). Developing brain and in utero cocaine exposure: Effects on neural ontogeny. Development and Psychopathology, 11, 685-714.

McFarlane, K. (2015). Care-criminalisation: The involvement of children in out-of-home care in the NSW criminal justice system. (Doctoral dissertation), University of New South Wales.

Mersky, J. P., \& Reynolds, A. J. (2007). Child maltreatment and violent delinquency: Disentangling main effects and subgroup effects. Child Maltreatment, 12(3), 246258. doi: $10.1177 / 1077559507301842$

Mersky, J. P., Topitzes, J., \& Reynolds, A. J. (2012). Unsafe at any age: Linking childhood and adolescent maltreatment to delinquency and crime. Journal of Research in Crime and Delinquency, 49(2), 295-318. doi: $10.1177 / 0022427811415284$

Moffitt, T. (1993). Adolescence-limited and life-course-persistent antisocial behavior: A developmental taxonomy. Psychological Review, 100(674-701).

Myers, R. H. (1990). Classical and modern regression with applications. Boston: PWSKent.

Odgers, C. L., Moretti, M., Burnette, M. L., Chauhan, P., Waite, D., \& Reppucci, N. D. (2007). A latent varable modeling approach to identifying subtypes of serious and violent female juvenile offenders. Aggressive Behavior, 33(4), 339-352.

Pardini, D. A., \& Frick, P. (2013). Multiple developmental pathways to conduct disorder: Current conceptualizations and clinical implications. Journal of Canadian Academic Child and Adolescent Psychiatry, 22(1), 20-25.

Piquero, A. R. (2015). What we know and what we need to know about developmental and life-course theories. Australian \& New Zealand Journal of Criminology, $48(3), 336-344$.

Raven, J., \& Court, J. (1998). Raven's prohressive matrices and vocabulary scales. Oxford, UK: Oxford Psychologists Press.

Roediger, K. J., Putt, J., Department of Families, H., Community Services and Indigenous Affairs, Group, A. C., Criminology, A. I. o., \& Welfare, A. I. o. H. a. (2011). Northern Territory Emergency Response evaliation report. Retrieved from $<$ http:// www.fahcsia.gov.au/our-responsibilities/indigenous-australians/publicationsarticles/northern-territory-emergency-response-evaluation-report-2011>

Ryan, J. (2006). Dependent Youth in Juvenile Justice: Do Positive Peer Culture Programs Work for Victims of Child Maltreatment? Research on Social Work Practice, 16(5), 511-519. doi: 10.1177/1049731506288458

Ryan, J., Herz, D., Hernandez, P. M., \& Marshall, J. M. (2007). Maltreatment and delinquency: Investigating child welfare bias in juvenile justice processing. Children and Youth Services Review, 29(8), 1035-1050. doi: 10.1016/j.childyouth.2007.04.002

Ryan, J., Hong, J. S., Herz, D., \& Hernandez, P. M. (2010). Kinship foster care and the risk of juvenile delinquency. Children and Youth Services Review, 32(12), 18231830. doi: 10.1016/j.childyouth.2010.08.003 
Ryan, J., \& Testa, M. F. (2005). Child maltreatment and juvenile delinquency: Investigating the role of placement and placement instability. Children and Youth Services Review, 27(3), 227-249. doi: 10.1016/j.childyouth.2004.05.007

Sampson, R. J., \& Laub, J. H. (1993). Crime in the making: Pathways and turning points through life. Cambridge MA: Harvard University Press.

Sampson, R. J., \& Laub, J. H. (2005). A life-course view of the development of crime. The Annals of the American Academy of Political and Social Science, 602(1), 1245.

Schuck, A. M., \& Widom, C. S. (2005). Understanding the role of neighborhood context in the long-term criminal consequences of child maltreatment. American Journal of Community Psychology, 36(3-4), 207-222. doi: 10.1007/s10464-005-8615-1

Smith, C. A., Ireland, T. O., \& Thornberry, T. P. (2005). Adolescent maltreatment and its impact on young adult antisocial behavior. Child Abuse \& Neglect, 29(10), 10991119. doi: 10.1016/j.chiabu.2005.02.011

Smith, C. A., Ireland, T. O., Thornberry, T. P., \& Elwyn, L. (2008). Childhood maltreatment and antisocial behavior: Comparison of self-reported and substantiated maltreatment. American Journal of Orthopsychiatry, 78(2), 173-186. doi: $10.1037 / 0002-9432.78 .2 .173$

Stewart, A., Livingston, M., \& Dennison, S. (2008). Transitions and turning points: Examining the links between child maltreatment and juvenile offending. Child Abuse \& Neglect, 32(1), 51-66. doi: 10.1016/j.chiabu.2007.04.011

Stine, R. A. (1995). A graphical interpretation of variance inflation factors. The American Statistician, 49, 53-56.

Stouthamer-Loeber, M., Loeber, R., Homish, D. L., \& Wei, E. (2001). Maltreatment of boys and the development of disruptive and delinquent behavior. Development and Psychopathology, 13, 941-955.

Thornberry, T. P., Henry, K. L., Ireland, T. O., \& Smith, C. A. (2010). The causal impact of childhood-limited maltreatment and adolescent maltreatment on early adult adjustment. Journal of Adolescent Health, 46(4), 359-365. doi: 10.1016/j.jadohealth.2009.09.011

Topitzes, J., Mersky, J. P., \& Reynolds, A. J. (2011). Child maltreatment and offending behavior: gender-specific effects and pathways. Criminal Justice and Behavior, 38(5), 492-510. doi: 10.1177/0093854811398578

Tzoumakis, S., Lussier, P., \& Corrado, R. R. (2014). The persistence of early childhood physical aggression: Examining maternal delinquency and offending, mental health, and cultural differences. Journal of Criminal Justice, 42(5), 408-420. doi: 10.1016/j.jcrimjus.2014.06.001

van der Put, C. E., \& de Ruiter, C. (2016). Child maltreatment victimization by type in relation to criminal recidivism in juvenile offenders. BMC Psychiatry, 16, 24. doi: 10.1186/s12888-016-0731-y

Verrecchia, P. J., Fetzer, M. D., Lemmon, J. H., \& Austin, T. L. (2010). An examination of direct and indirect effects of maltreatment dimensions and other ecological risks on persistent youth offending. Criminal Justice Review, 35(2), 220-243. doi: $10.1177 / 0734016809360327$

Vig, S., Chinitz, S., \& Sbulman, L. (2005). Young children in foster care. Multiple vulnerabilities and complex service needs. Infants \& Young Children, 18(2), 147160.

Widom, C. S. (1991). The role of placement experiences in mediating the criminal consequences of early childhood victimization. American Journal of Orthopsychiatry, 61(2), 195-209. 
Widom, C. S., \& Morris, S. (1997). Accuracy of adult recollections of childhood victimization: Part 2. Childhood sexual abuse. Psychological Assessment, 9(1), 3446.

Widom, C. S., Schuck, A. M., \& White, H. R. (2006). An examination of pathways from childhood victimization to violence: The role of early aggression and problematic alcohol use. Violence and Victims, 21(6), 675-690.

Wilson, H. W., Stover, C. S., \& Berkowitz, S. J. (2009). The relationship between childhood violence exposure and juvenile antisocial behavior: a meta-analytic review. Journal of Child Psychology and Psychiatry, 50(7), 769-779. doi: 10.1111/j.1469-7610.2008.01974.x

Wolff, K. T., \& Baglivio, M. T. (2016). Adverse Childhood Experiences, Negative Emotionality, and Pathways to Juvenile Recidivism. Crime \& Delinquency, 63(12), 1495-1521. doi: 10.1177/0011128715627469

World Health Organisation. (2002). Youth Violence. In World Health Organisation (Ed.), World report on violence and health. Geneva: World Health Organization.

Yang, J., McCuish, E. C., \& Corrado, R. R. (2017). Foster care beyond placement: Offending outcomes in emerging adulthood. Journal of Criminal Justice, 53, 4654. doi: 10.1016/j.jcrimjus.2017.08.009 
Table 1. Descriptive Statistics of Independent Variables among the Full Sample of Offenders, Male/Female and Indigenous/non-Indigenous Subsamples

\begin{tabular}{|c|c|c|c|c|c|c|c|}
\hline & $\begin{array}{l}\text { Full sample } \\
(\mathrm{N}=1819)\end{array}$ & $\begin{array}{c}\text { Males } \\
(\mathrm{N}=1540)\end{array}$ & $\begin{array}{l}\text { Females } \\
(\mathrm{N}=278)\end{array}$ & $\begin{array}{l}\text { Indigenous } \\
(\mathrm{N}=485)\end{array}$ & $\begin{array}{c}\text { Non- } \\
\text { Indigenous } \\
(\mathrm{N}=1334)\end{array}$ & $\begin{array}{l}\text { Male vs. } \\
\text { Female }\end{array}$ & $\begin{array}{c}\text { Indigenous vs. } \\
\text { Non- } \\
\text { Indigenous }\end{array}$ \\
\hline & $\mathrm{N}(\%)$ & $\mathrm{N}(\%)$ & $\mathrm{N}(\%)$ & $\mathrm{N}(\%)$ & $\mathrm{N}(\%)$ & $x^{2}$ & $x^{2}$ \\
\hline Any violent crime convictions & $1205(66.2)$ & $1000(64.9)$ & $204(73.4)$ & $353(72.8)$ & $852(63.9)$ & $7.51 * *$ & $12.64 * * *$ \\
\hline \multicolumn{8}{|l|}{ Family and peer risk indicators } \\
\hline Parental death & $249(13.7)$ & $211(13.7)$ & $37(13.3)$ & $97(20.0)$ & $152(11.4)$ & 0.03 & $22.30 * * *$ \\
\hline Parental separation & $1090(59.9)$ & $911(59.2)$ & $179(64.4)$ & $297(61.2)$ & $793(59.4)$ & 2.69 & 0.48 \\
\hline Family history crime & $1068(58.7)$ & $882(57.3)$ & $185(66.5)$ & $360(74.2)$ & $708(53.1)$ & $8.10 * *$ & $65.18 * * *$ \\
\hline Family history substance abuse & $860(47.3)$ & $688(44.7)$ & $171(61.5)$ & $280(57.7)$ & $580(43.5)$ & $27.06^{* * *}$ & $28.47 * * *$ \\
\hline Household conflict & $329(18.1)$ & $251(16.3)$ & $78(28.1)$ & $67(13.8)$ & $262(19.6)$ & $36.27 * * *$ & $8.39 * *$ \\
\hline Mother-child relationship & $169(9.3)$ & $128(8.3)$ & $41(14.7)$ & $29(6.0)$ & $140(10.5)$ & $11.57 * * *$ & $8.61 * *$ \\
\hline Father-child relationship & $222(12.2)$ & $176(11.4)$ & $46(16.5)$ & $43(8.9)$ & $179(13.4)$ & $5.75^{*}$ & $6.88 * *$ \\
\hline Stepparent-child relationship & $163(9.0)$ & $128(8.3)$ & $35(12.6)$ & $35(7.2)$ & $128(9.6)$ & $5.28 *$ & 2.47 \\
\hline Peer criminality & $1134(62.3)$ & $989(64.2)$ & $144(19.8)$ & $307(63.3)$ & $827(62.0)$ & $15.48 * * *$ & 0.26 \\
\hline \multicolumn{8}{|l|}{ Individual risk factors } \\
\hline \multicolumn{8}{|l|}{ Intelligence and education } \\
\hline Intellectual ability & $365(20.1)$ & $310(20.1)$ & $55(19.8)$ & $127(26.2)$ & $238(17.8)$ & 0.02 & $15.44 * * *$ \\
\hline School problems & $1704(93.7)$ & $1449(94.1)$ & $254(91.4)$ & $435(89.7)$ & $1269(95.1)$ & $2.95 \dagger$ & $17.75 * * *$ \\
\hline
\end{tabular}


Reading difficulty

Substance use

Overall substance use

Problematic alcohol use

Problematic marijuana use

Mental health problems

Chronic depressive mood

Suicide ideation

Suicide attempt

Behavior problems

Anger

Aggression

Maltreatment factors

Any notification
Any substantiation
Physical abuse
Sexual abuse
Emotional abuse
Neglect
Multi-type maltreatment
Childhood-limited
Adolescent-limited

477 (26.2)

$420(27.3)$

$56(20.1)$

199 (41.0)

$278(20.8)$

$6.19^{*}$

$74.95 * * *$

$\begin{array}{lllllll}1538(84.6) & 1305(84.7) & 232(83.5) & 420(86.6) & 1118(83.4) & 0.30 & 2.12 \\ 1258(69.2) & 1075(69.8) & 182(65.5) & 329(67.8) & 929(69.6) & 2.08 & 0.54 \\ 1290(70.9) & 1096(71.2) & 193(69.4) & 360(74.2) & 930(69.7) & 0.35 & 3.51 \dagger\end{array}$

$\begin{array}{cccccccc}171(9.4) & 131(8.5) & 40(14.4) & 42(8.7) & 129(9.7) & 9.56 * * & 0.43 \\ 264(14.5) & 179(11.6) & 85(30.6) & 71(14.6) & 193(14.5) & 54.94 * * * & 2.31 \\ 410(22.5) & 290(18.8) & 119(42.8) & 106(21.9) & 304(22.8) & 62.61 * * * & 6.69 * * \\ 1037(57.0) & 848(55.1) & 188(67.6) & 250(51.5) & 787(59.0) & 17.12 * * * & 7.15 * * \\ 1286(70.7) & 1110(72.1) & 175(62.9) & 341(70.3) & 945(70.8) & 9.47 * * & 0.05\end{array}$

\begin{tabular}{|c|c|c|c|c|c|c|}
\hline 1229 (67.6) & $983(63.8)$ & $245(88.1)$ & $372(76.7)$ & $857(64.2)$ & $63.43 * * *$ & $25.19 * * *$ \\
\hline $695(38.2)$ & $545(35.4)$ & $149(53.6)$ & $238(49.1)$ & $457(34.3)$ & $33.08 * * *$ & $33.06 * * *$ \\
\hline $382(21.0)$ & $308(20.0)$ & $73(26.3)$ & $107(22.1)$ & $275(20.6)$ & $5.57 *$ & 0.45 \\
\hline 107 (5.9) & $49(3.2)$ & $58(20.9)$ & $26(5.4)$ & $81(6.1)$ & $132.91 * * *$ & 0.33 \\
\hline $166(9.1)$ & $134(8.7)$ & $31(11.2)$ & $57(11.8)$ & $109(8.2)$ & 1.71 & $5.50 *$ \\
\hline 387 (21.3) & $313(20.3)$ & $74(26.6)$ & $159(32.8)$ & $228(17.1)$ & $5.57^{*}$ & $52.29 * * *$ \\
\hline $278(15.3)$ & $211(13.7)$ & $68(23.7)$ & $88(18.1)$ & $190(14.2)$ & $18.38 * * *$ & $4.18 *$ \\
\hline $281(15.4)$ & $267(17.3)$ & $14(5.0)$ & $80(16.5)$ & $201(15.1)$ & $27.27 * * *$ & 0.56 \\
\hline 192 (10.6) & $150(9.7)$ & $42(15.1)$ & $35(7.2)$ & $157(11.8)$ & $7.18 * *$ & $7.81 * *$ \\
\hline
\end{tabular}


Placement factors

\begin{tabular}{|c|c|c|c|c|c|c|c|}
\hline Ever placed & $476(26.2)$ & $362(23.5)$ & $113(40.6)$ & $155(32.0)$ & $321(24.1)$ & $47.59 * * *$ & $11.48 * *$ \\
\hline Foster care & $170(9.3)$ & $124(8.1)$ & $46(16.5)$ & $55(11.3)$ & $115(8.6)$ & $15.77 * * *$ & $3.11 \dagger$ \\
\hline Residential care & $155(8.5)$ & $109(7.1)$ & $45(16.2)$ & $31(6.4)$ & $124(9.3)$ & $43.12 * * *$ & $3.85^{*}$ \\
\hline \multirow[t]{2}{*}{ Kinship care } & $49(2.7)$ & $39(2.5)$ & $10(3.6)$ & $26(5.4)$ & $23(1.7)$ & 0.23 & $17.95 * * *$ \\
\hline & $\mathrm{M}(\mathrm{SD})$ & $\mathrm{M}(\mathrm{SD})$ & $\mathrm{M}(\mathrm{SD})$ & $\mathrm{M}(\mathrm{SD})$ & $\mathrm{M}(\mathrm{SD})$ & $t$ & $t$ \\
\hline ubstantiations (recurrence) & $1.44(2.01)$ & $1.39(1.96)$ & $1.61(2.20)$ & $1.70(2.30)$ & $1.32(1.86)$ & 1.54 & $2.85^{* *}$ \\
\hline \multirow[t]{2}{*}{ lacement changes (instability) } & 10.50 & $9.59(9.96)$ & $13.50(12.86)$ & $8.19(9.94)$ & $11.62(11.07)$ & $2.96^{* *}$ & $3.27 * *$ \\
\hline & $(10.83)$ & & & & & & \\
\hline e at first placement & $7.87(4.39)$ & $7.82(4.28)$ & $7.96(4.74)$ & $7.29(4.54)$ & $8.15(4.30)$ & 0.28 & $2.00 *$ \\
\hline
\end{tabular}

Note. $\uparrow p<.1 . * p<.05 .{ }^{* *} p<.01 .{ }^{* * *} p<.001$. 
Table 2. Odds Ratios and Confidence Intervals for Predictors of Violent Crime Convictions

\begin{tabular}{|c|c|c|c|c|c|c|c|c|c|c|}
\hline & \multicolumn{2}{|c|}{ Model 1} & \multicolumn{2}{|c|}{ Model 2} & \multicolumn{2}{|c|}{ Model 3} & \multicolumn{2}{|c|}{ Model 4} & \multicolumn{2}{|c|}{ Model 5} \\
\hline & OR & $95 \% \mathrm{CI}$ & OR & $95 \% \mathrm{CI}$ & OR & $95 \% \mathrm{CI}$ & OR & $95 \% \mathrm{CI}$ & OR & $95 \% \mathrm{CI}$ \\
\hline Physical abuse & $1.29 \dagger$ & {$[0.98,1.67]$} & 1.21 & {$[0.92,1.59]$} & 1.25 & {$[0.87,1.80]$} & 1.30 & {$[0.90,1.88]$} & 1.29 & {$[0.89,1.86]$} \\
\hline Persistent maltreatment & $1.59 * * *$ & {$[1.28,1.97]$} & $1.47 * * *$ & {$[1.18,1.83]$} & $1.40 * *$ & {$[1.07,1.83]$} & $1.34 *$ & {$[1.02,1.76]$} & $1.33 *$ & {$[1.01,1.76]$} \\
\hline Foster care & & & $1.50 \dagger$ & {$[0.93,2.43]$} & 1.55 & {$[0.89,2.71]$} & 1.53 & {$[0.86,2.72]$} & 3.62 & {$[0.61,21.31]$} \\
\hline Residential care & & & 0.21 & {$[0.83,2.29]$} & $1.70 \dagger$ & {$[0.93,3.12]$} & $1.71 \dagger$ & {$[0.92,3.17]$} & 4.72 & {$[0.71,31.55]$} \\
\hline Gender (Males) & & & & & 1.35 & {$[0.92,2.00]$} & $1.41 \dagger$ & {$[0.95,2.11]$} & $1.76^{*}$ & {$[1.12,2.76]$} \\
\hline Indigenous & & & & & $1.46^{* *}$ & {$[1.09,1.97]$} & $1.52 * *$ & {$[1.12,2.06]$} & $1.51 * *$ & {$[1.11,2.04]$} \\
\hline Parent death & & & & & 1.22 & {$[0.85,1.77]$} & 1.24 & {$[0.85,1.80]$} & 1.25 & {$[0.86,1.82]$} \\
\hline Household conflict & & & & & $1.42 *$ & {$[1.07,1.90]$} & $1.31 \dagger$ & {$[0.98,1.77]$} & $1.32 \dagger$ & {$[0.98,1.77]$} \\
\hline Anger & & & & & & & $1.42 * * *$ & {$[1.09,1.84]$} & $1.41 * * *$ & {$[1.09,1.84]$} \\
\hline Aggression & & & & & & & $1.65 * * *$ & {$[1.26,2.18]$} & $1.66^{* * *}$ & {$[1.26,2.19]$} \\
\hline Foster care $\mathrm{x}$ Gender & & & & & & & & & 0.50 & {$[0.13,1.91]$} \\
\hline Residential care $\mathrm{x}$ Gender & & & & & & & & & 0.47 & {$[0.12,1.87]$} \\
\hline$-2 \mathrm{LLR}$ & & 2295.20 & & 2285.27 & & 1512.43 & & 1474.00 & & 1468.23 \\
\hline
\end{tabular}

Note. $\dagger p<.1 . * p<.05 . * * p<.01 . * * * p<.001$. 